Roselle C. Bargo, MD'

Samantha S. Castañeda, MD $1,2,3$

'Department of Otorhinolaryngology Head and Neck Surgery

Jose R. Reyes Memorial Medical Center

${ }^{2}$ Department of Otorhinolaryngology Head and Neck Surgery

Rizal Medical Center

${ }^{3}$ Department of Otorhinolaryngology Head and Neck Surgery

The Medical City

\section{Alternative self-retaining retractors for head and neck surgery}

\author{
ABSTRACT \\ Objective: To design affordable, easy-to-use self-retaining retractors that can provide adequate \\ exposure of the operative area in head and neck surgery
}

\section{Methods:}

\author{
Design: Surgical Instrumentation \\ Setting: Tertiary government hospital \\ Subjects: One
}

Results: Self-retaining retractors were designed and fabricated from stainless steel with tissue prongs on one end and a loop for rubber-band attachment to surgical drapes via a towel clip on the other end. Varying prong lengths were devised for different depths of required retraction. Traction tension could be adjusted by varying rubber-band attachment distance. The retractors were tested on a patient undergoing open reduction and internal fixation for a mandibular fracture and evaluated according to ease of application, adequacy of exposure and tissue trauma.

Conclusion: The self-retaining retractors may be affordable alternatives to commercially-available self-retaining retractors. They are easily applied with adjustable tension and depth of retraction that can provide adequate exposure with minimal tissue trauma.

\section{Key words: self-retaining retractor, instrumentation}

Tissue retractors have been an integral part of surgical instrumentation throughout its history and various types in different shapes and sizes are available for various procedures. Generally, retractors reposition tissues in order to expose the operative site and facilitate surgery. Ease of application and a balance between appropriate tension and minimal trauma provide adequacy of exposure. Tissues must be handled gently to preserve cellular integrity. Excessive pressure may crush tissue, cause ischemia, necrosis and compromise wound healing. Ideally, skin is retracted with hooks and when needed, fine-toothed forceps that are closed with minimal tension.' Ideal retraction balances tissue tension with exposure of deeper tissues, facilitating surgical dissection with a knife or tissue scissors. ${ }^{2}$

Self-retaining retractors obviate the need for additional hands, freeing surgeons for other tasks. Such instruments may retract tissues in a single or multiple directions under fixed or variable tension. For instance, the Dingman and Weitlaner retractors both retract tissues in two opposite directions under fixed (once locked) tension. Inspired by the ingenious use of a fish hook observed on a visit to the Chang Gung Hospital, we designed alternative instruments that retract tissues in a single direction under variable (due to rubber-band) tension. 


\section{SURGICAL INNOVATIONS AND INSTRUMENTATION}

\section{MATERIALS AND METHODS}

The retractors were fabricated from stainless steel, each with three parts- the body, proximal and distal end (Figure 1). The flat body of each retractor measured $5 \mathrm{~cm} \times 1 \mathrm{~cm} \times 0.2 \mathrm{~cm}$. The proximal end was curved circularly inward leaving a $0.1 \mathrm{~cm}$ gap between the tip and body of the retractor for rubber-band insertion. The distal ends were curved into two blunt-ended prongs, each $0.2 \mathrm{~cm}$ wide, with varying depths of $1 \mathrm{~cm} ., 2 \mathrm{~cm}$. and $4 \mathrm{~cm}$. respectively (Figure 2 ).
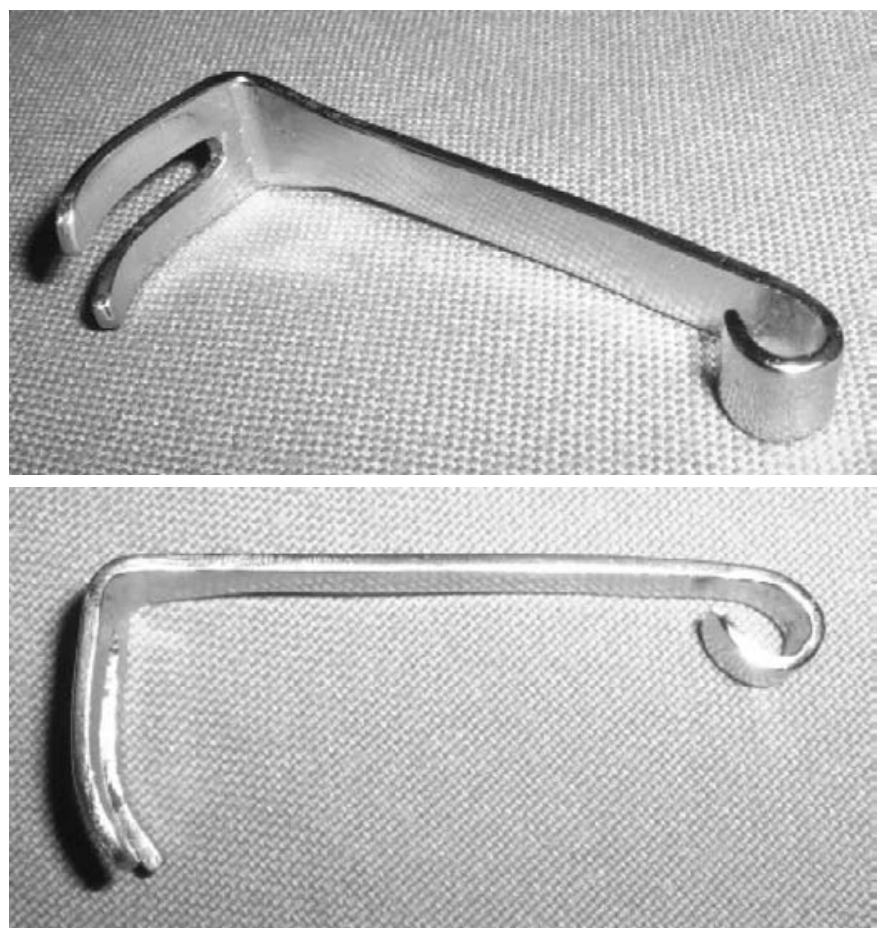

Figure 1. The self-retaining retractor
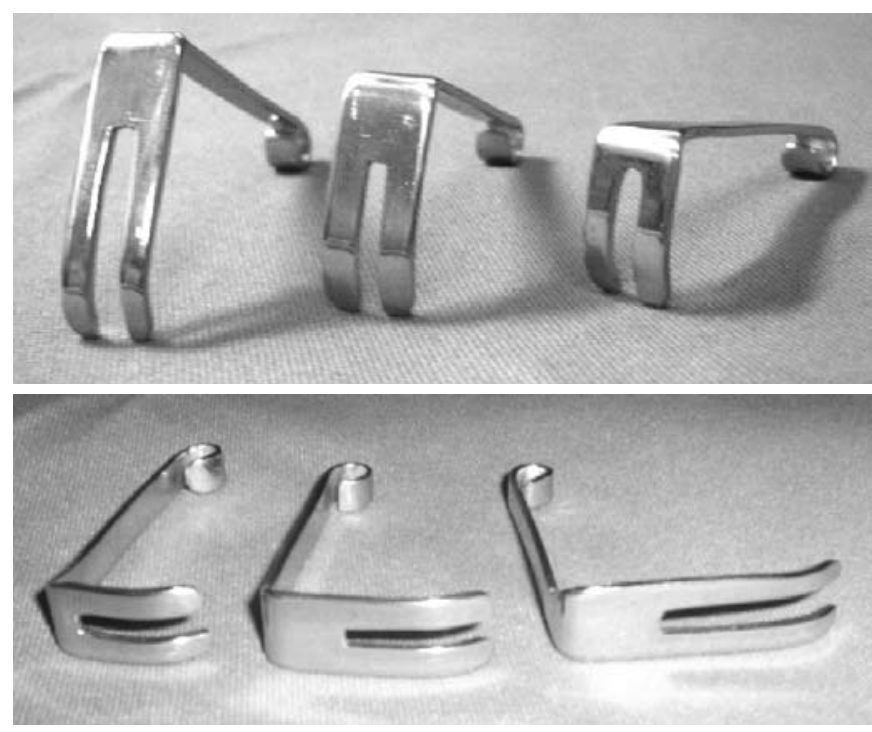

Figure 2. Different prong lengths of the self retaining retractor

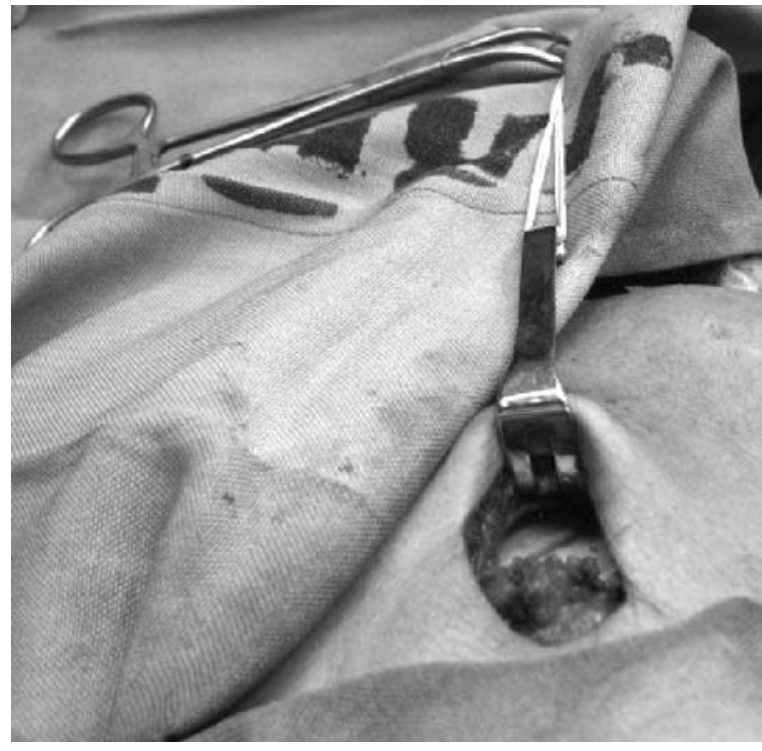

Figure 3. The retractor used intra-operatively

\section{RESULTS}

The self-retaining retractors were tested on a patient undergoing open reduction and internal fixation for a mandibular fracture (Figure 3). The retractors were easily applied and rubber-band tension easily adjusted by varying the distance of the towel clip from the retractor. Exposure of the operative site was adequate for dissection, fracture reduction and internal fixation with plates and screws. No gross tissue trauma was observed. The post-operative course of the patient was uneventful and comparable to similar procedures using conventional retractors.

\section{DISCUSSION}

Necessity is the mother of invention. In a developing nation, costcutting involves searching for inexpensive instrumentation as much as minimizing manpower requirements. Our alternative self-retaining retractors achieve both. Their properties effectively free an extra hand for other tasks while achieving their purpose. Other commercially available self-retaining retractors are costly, ranging from $\mathrm{PhP} 5,000$ to $\mathrm{PhP} 10,000$ each. Our alternative self-retaining retractors only cost $\mathrm{PhP} 350$ making them an affordable alternative. They are easily applied with adjustable tension and depth of retraction that can provide adequate exposure with minimal tissue trauma. We recommend further trials in a larger series and in comparison with similar unidirectional self-retaining devices.

\section{REFERENCES}

1. Georgiade G, Riefkohl R, Levin LS. Basic principles of surgical techniques. Plastic, Maxillofacial and Reconstructive Surgery. $3^{\text {rd }}$ ed. Maryland, USA: Williams and Wilkins; 1997. p.11.

2. Sherris D, Kern E. Mayo Clinic: Basic Surgical Skills. Minnesota, USA: Mayo foundation for medical education and research; 1999. pp.32-33. 